\title{
Molecular Design of $\left[\mathrm{Co}_{11} \mathrm{C}_{2}(\mathrm{CO})_{23}\right]^{3-}$ Both Enhances Rate and Lowers Overpoten- tial for Fast C-H Bond Formation with $\mathrm{CO}_{2}$
}

\author{
Santanu Pattanayak, Louise A. Berben* \\ Department of Chemistry, University of California, Davis, California, Davis, 95616, United States
}

\begin{abstract}
For electrochemically driven solar fuel-forming reactions thermochemistry dictates that the rate of the reaction will scale linearly with the overpotential of the catalyst, and for a molecular catalyst, overpotential is related to the redox couple (or $E_{1 / 2}$ ) of the molecule. Enhancements in catalytic rates therefore rely on optimization of kinetic factors and this must be achieved by tuning catalyst structure and thereby reaction mechanism to influence reaction kinetics. In this report we use kinetic influences on the two chemical steps in the mechanism for $\mathrm{CO}_{2}$ electroreduction to achieve fast $\mathrm{C}-\mathrm{H}$ bond-formation and formate formation at $127 \mathrm{M}^{-1} \mathrm{~s}^{-1}$ with an overpotential of just $\sim 10 \mathrm{mV}$. Compared with molecular catalysts that have similar overpotential, this rate is enhanced by five orders of magnitude. As an alternative comparison, for reported molecular catalysts with similar rate, this overpotential is lowered by $100 \mathrm{mV}$. These combined enhancements derive from a detailed understanding of the catalyst mechanism. Moreover, the principles elucidated here for molecular design are general and can guide future and further improved catalyst development in hydride transfer and $\mathrm{X}-\mathrm{H}$ bond forming reactions $(\mathrm{X}=\mathrm{C}$, $\mathrm{N}$, or other).
\end{abstract}

\section{Main Text}

Transformation of $\mathrm{CO}_{2}$ to $\mathrm{C}-\mathrm{H}$ bond containing chemicals and fuels by electrochemical means potentially offers a sustainable approach to renewable energy storage. ${ }^{1,2,3,4,5,6,7,8}$ The chemistry of C-H bond formation with $\mathrm{CO}_{2}$ has received significant attention across a broad spectrum of research disciplines, and that work has led to improved outcomes in performance of solar fuels catalysts, ${ }^{9,10,11,12,13,14,15}$ along with a better understanding of reaction mechanism and catalyst design. A foremost remaining challenge in this area is to increase rates for product formation whilst lowering the overpotential for the reaction and maintaining selectivity. This report addresses design principles for managing reaction kinetics to both lower the overpotential and increase the rate of $\mathrm{C}-\mathrm{H}$ bond formation in C-H bond-formation with $\mathrm{CO}_{2}$.

Desirable products of $\mathrm{CO}_{2}$ reduction require proton equivalents to generate metal hydrides (Scheme 1). However, metal hydrides are competent for direct proton reduction to $\mathrm{H}_{2}$. Contributions from a number of research groups have demonstrated how we can use molecular design for thermochemical control of reaction chemistry to achieve selectivity for $\mathrm{C}-\mathrm{H}$ bond formation over $\mathrm{H}_{2}$ evolution, ${ }^{16,17,18,19,20,21,22,23}$ but that thermochemical control alone does not produce fast rates for $\mathrm{C}-\mathrm{H}$ bond formation with $\mathrm{CO}_{2}{ }^{24}$ 


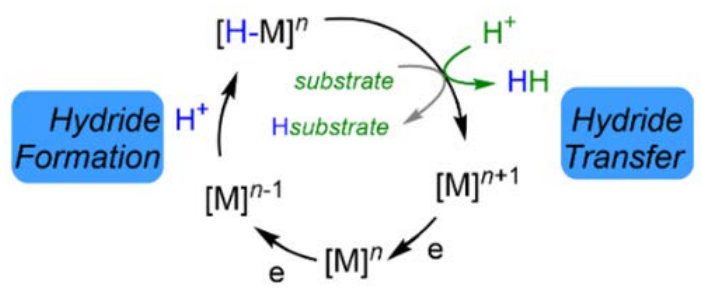

Several other reports hint at kinetic control of reaction selectivity in C-H bond formation to produce formate, and these include use of bulky substituents to select for substrate approach to an active site. ${ }^{25,26}$ Approaches to kinetic enhancement of reaction rate can also focus on reaction conditions, rather than catalyst design, and successful examples of this approach include stabilization of transition states for hydride transfer to $\mathrm{CO}_{2}$ by choice of solvent, ${ }^{27,28,29,30,31}$ use of hydride transfer mediators, ${ }^{32}$ or additions of base or alcohol. ${ }^{33,34}$ Metal carbonyl clusters (MCC's) offer a surface of metal-metal bonds that are capped by fluxional CO ligands. ${ }^{35}$ These multiple metalmetal bonds serve as multiple sites for protonation and this provides a kinetic boost to the rate of cluster-hydride formation in an electrochemically driven reaction. That principle was illustrated with both $\left[\mathrm{Co}_{11} \mathrm{C}_{2}(\mathrm{CO})_{23}\right]^{3-}\left(\mathbf{1}^{3-}\right)$ and $\left[\mathrm{Co}_{13} \mathrm{C}_{2}(\mathrm{CO})_{24}\right]^{4-}$ which undergo fast PT following one-electron reduction, to afford $\left[\mathrm{H}-\mathrm{Co}_{11} \mathrm{C}_{2}(\mathrm{CO})_{23}\right]^{3-}(\mathrm{H}-$ 1) $)^{3-}$ and $\left[\mathrm{H}-\mathrm{Co}_{13} \mathrm{C}_{2}(\mathrm{CO})_{24}\right]^{4-}$ at $3 \times 10^{8}$ and $2.9 \times 10^{9} \mathrm{M}^{-1} \mathrm{~s}^{-1}$, respectively (Scheme 1 , Chart 1$){ }^{36,37}$ These hydride formation rates - obtained from a cyclic voltammetry (CV) measurement of the proton transfer (PT) rate appear to be limited only by diffusion of protons in solution.

Chart 1. Line drawing of $\left[\mathrm{Co}_{11} \mathrm{C}_{2}(\mathrm{CO})_{23}\right]^{3-}\left(\mathbf{1}^{3-}\right)$.

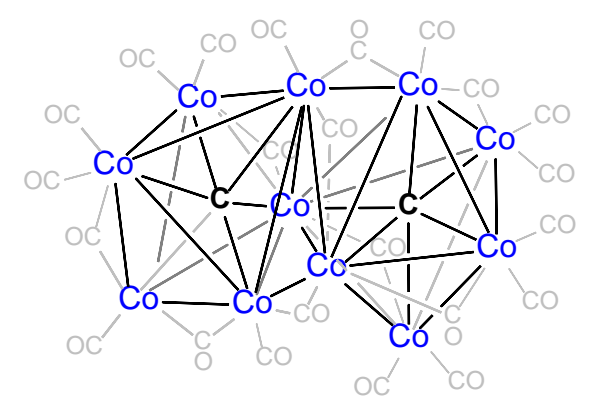

This kinetic effect, where the multiple sites for protonation on the surface of each cluster effectively provide a higher concentration of protonation sites and enhance hydride formation rates, is akin to the operation of proton relays where Lewis basic sites surrounding a catalyst enhance the concentration of protons close to the active site and speed up proton transfer (PT) events. ${ }^{38}$ The significant difference between MCC's and proton relays is that MCC's speed up only the PT for hydride formation (Scheme 1); whereas proton relays speed up both hydride formation and hydride transfer and therefore are only useful when making $\mathrm{H}_{2}$ (Scheme 1). The behavior of MCC's is therefore more similar to that of nanomaterials or heterogeneous electrocatalysts which promote fast hydride formation via the Volmer mechanism. However, we can characterize MCC's in detail using the powerful tools associated with homogeneous, molecular (electro)chemistry.

When conceiving of the work reported herein, we reasoned that we know how to use thermochemical control to choose formate formation over $\mathrm{H}_{2}$ evolution in the hydride transfer step of the catalytic cycle (Scheme 1 ). ${ }^{16}$ Moreover, if hydride transfer is gated by thermochemistry and is orders of magnitude slower than hydride formation, then the concentration of $(\mathrm{H}-\mathbf{1})^{3-}$ must build up in solution during catalysis, and this will offer a kinetic boost to the formate formation rate without any loss to the selectivity for formate formation (Scheme 2). We further noted during this experimental design that the fast rate for PT to afford (H-1) $)^{3-}$ offers a kinetically-derived lowering of 
the overpotential for the reaction, on the order of $\sim 180 \mathrm{mV}$ because a fast chemical step following an ET event results in anodic shift of the reduction peak potential of any molecule.

\section{Scheme 2. The structure of MCC's enables independent control and enhancement of hydride formation $\left(k_{1}\right)$ and hydride transfer $\left(k_{2}\right)$ rates.}

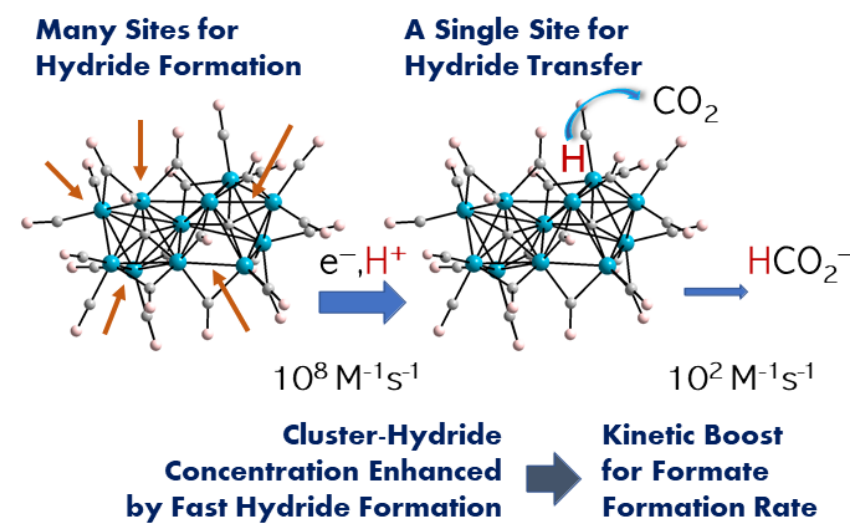

The combined kinetic effects described in the preceding paragraph result in both a low overpotential (due to fast hydride formation), and a fast rate for $\mathrm{C}-\mathrm{H}$ bond formation (due to fast hydride transfer). Using these combined elements of tailored molecular design in $\mathbf{1}^{3-}$, formate is generated at an overpotential of $60 \mathrm{mV}$ and with rate of $127 \mathrm{M}^{-1} \mathrm{~s}^{-1}$ using $\mathbf{1}^{3-}$ in $0.1 \mathrm{M} \mathrm{Bu}_{4} \mathrm{NBF}_{4} \mathrm{MeCN} / \mathrm{H}_{2} \mathrm{O}$ (95:5), and this is benchmarked against existing catalysts using a Tafel-style plot presented later in this report. The well-understood structural origin of the mechanistic details and outcomes presented herein will further enable application of these kinetic strategies in future catalyst designs and improvements.

\section{Results and Discussion}

To study catalysis by $\mathbf{1}^{3-}$, we prepared samples of $\left(\mathrm{PhCH}_{2} \mathrm{NMe}_{3}\right)_{2}\left[\mathrm{Co}_{11} \mathrm{C}_{2}(\mathrm{CO})_{23}\right]\left(\mathbf{1}^{2-}\right)$ following a previously published method $\left(\mathrm{PhCH}_{2} \mathrm{NMe}_{3}{ }^{+}=\right.$Benzyl ammonium cation). ${ }^{39}$ The $\mathrm{CV}$ of $0.05 \mathrm{mM} \mathbf{1}^{2-}$ recorded in $0.1 \mathrm{M}$ $\mathrm{Bu}_{4} \mathrm{NBF}_{4} \mathrm{MeCN}$ solution under $1 \mathrm{~atm} \mathrm{~N}_{2}$ shows three reversible redox couples with $E_{1 / 2}=-0.2$, -0.57 and $-0.95 \mathrm{~V}$ vs. SCE which were assigned as the $\mathbf{1}^{1-/ 2-}, \mathbf{1}^{2-/ 3-}$, and $\mathbf{1}^{3-/ 4-}$ couples, respectively (Figure S1). ${ }^{37,39}$ For experiments probing the catalytic activity of $\mathbf{1}^{3-}$ this species is generated in the $\mathrm{CV}$ measurement in all discussions below.

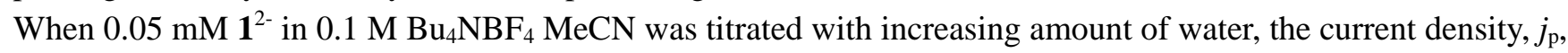
at $-1.054 \mathrm{~V}$ increases linearly up to $4 \%(2.2 \mathrm{M}) \mathrm{H}_{2} \mathrm{O}$ after which the changes in current density were very small (Figure 1 inset). This increase in $j_{\mathrm{p}}$ suggests that formation of $\mathbf{1}^{4-}$ is very quickly followed by PT to afford $(\mathrm{H}-\mathbf{1})^{3-}$ and that another PT closes a catalytic cycle for HER; the catalytic half-wave potential $\left(E_{\mathrm{cat} / 2}\right)$ almost coincides with the half wave potential of $\mathbf{1}^{3-/ 4-}$ couple. CV's of $0.05 \mathrm{mM} \mathrm{1}^{2-}$ collected under 1 atm $\mathrm{CO}_{2}$ in $0.1 \mathrm{M} \mathrm{Bu}_{4} \mathrm{NBF}_{4}$ $\mathrm{MeCN} / \mathrm{H}_{2} \mathrm{O}(95: 5)$ showed a further increase in $j_{\mathrm{p}}$ at $-1.054 \mathrm{~V}$, relative to the CV's collected under 1 atm $\mathrm{N}_{2}$, and this suggests that a catalytic reaction has occurred where hydride is transferred to $\mathrm{CO}_{2}$ to afford formate (Figure 1). 


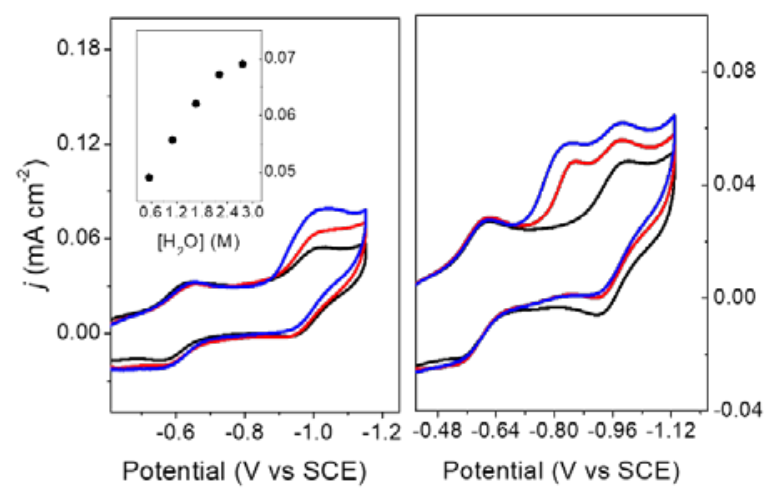

Figure 1. (left) CV's of $0.05 \mathrm{mM} \mathrm{1}^{2-}$ in $0.1 \mathrm{M} \mathrm{Bu}_{4} \mathrm{NBF}_{4} \mathrm{MeCN}$ solution (black); in $0.1 \mathrm{M} \mathrm{Bu}_{4} \mathrm{NBF}_{4} \mathrm{MeCN}_{2} \mathrm{H}_{2} \mathrm{O}$ (95:5) under $1 \mathrm{~atm} \mathrm{~N}_{2}$ (red); in $0.1 \mathrm{M} \mathrm{Bu}_{4} \mathrm{NBF}_{4} \mathrm{MeCN} / \mathrm{H}_{2} \mathrm{O}$ (95:5) under $1 \mathrm{~atm} \mathrm{CO}_{2}$ (blue). Inset: Plot of $j_{\mathrm{p}}$ vs. $\left[\mathrm{H}_{2} \mathrm{O}\right]$ in $0.1 \mathrm{M} \mathrm{Bu}_{4} \mathrm{NBF}_{4} \mathrm{MeCN}$ under $1 \mathrm{~atm} \mathrm{~N}_{2}$. (right) CV's of $0.05 \mathrm{mM} \mathbf{1}^{2-}$ in $0.1 \mathrm{MBu}_{4} \mathrm{NBF}_{4} \mathrm{MeCN}$ solution (black); under 1 atm $\mathrm{N}_{2}$, in $0.1 \mathrm{M} \mathrm{Bu}_{4} \mathrm{NBF}_{4} \mathrm{MeCN} / \mathrm{H}_{2} \mathrm{O}$ (99.3:0.7) under 1 atm $\mathrm{N}_{2}$ (red); in $0.1 \mathrm{M} \mathrm{Bu}_{4} \mathrm{NBF}_{4}$ $\mathrm{MeCN} / \mathrm{H}_{2} \mathrm{O}$ (99.3:0.7) under $1 \mathrm{~atm} \mathrm{CO}_{2}$ (blue).

Characterization of Formate. Controlled potential electrolysis (CPE) experiments carried out under both 1 atm $\mathrm{N}_{2}$ and $1 \mathrm{~atm} \mathrm{CO}_{2}$ were performed to identify the product formed when increases in current are observed in the CV experiments. CPE experiments $-1.064 \mathrm{~V}$ over 40 min were followed by analysis of the head space using gas chromatography with thermal conductivity detector (GC-TCD) and analysis of the solution using proton NMR spectroscopy. We determined that the Faradaic efficiency (FE) for formate and $\mathrm{H}_{2}$ production are $75(5)$ and 15(2) \%, respectively (Table S1, Figures S2 - S4, see SI for experimental details). CPE experiments performed using anisidinium tetrafluoroborate $\left(\mathrm{AnsdH}^{+}\right)$as the source of protons under $1 \mathrm{~atm} \mathrm{CO}_{2}$ were run at $-0.9 \mathrm{~V}$, and

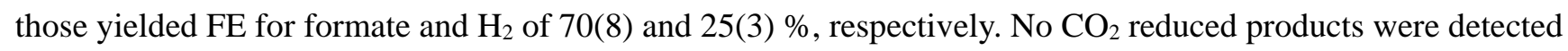
by proton NMR when the CPE experiments were carried out under $1 \mathrm{~atm} \mathrm{~N}_{2}$ or in the absence of $\mathbf{1}^{2-}$ under $1 \mathrm{~atm}$ $\mathrm{CO}_{2}$. CPE experiments were also run with the used electrodes from CPE experiments containing $\mathbf{1}^{2-}$ and those also produced no carbon-containing products. SEM-EDX measurements performed on used electrodes revealed no deposited Co on the glassy carbon (Figure S5).

Mechanistic Studies of Hydride Formation. Our first step toward understanding the origins of kinetic enhancements promoting fast and low overpotential formate formation by $\mathbf{1}^{3-}$ was to measure the rate for hydride formation ( $k_{1}$, Scheme 3) in $\mathrm{MeCN} / \mathrm{H}_{2} \mathrm{O}(95: 5)$ under both a $\mathrm{N}_{2}$ and $\mathrm{CO}_{2}$ atmosphere, where clusters of $\mathrm{H}_{2} \mathrm{O}$ $\mathrm{MeCN}$ (under $\mathrm{N}_{2}$ and $\mathrm{CO}_{2}$ ) and/or carbonic acid (under $\mathrm{CO}_{2}$ ), respectively, are the proton sources for hydride formation. Clusters of $\mathrm{H}_{2} \mathrm{O}-\mathrm{MeCN}$ which serve as proton source in $\mathrm{MeCN} / \mathrm{H}_{2} \mathrm{O}(95: 5)$ have $\mathrm{p} K_{\mathrm{a}} 39-41,{ }^{40}$ and carbonic acid produced from $33 \mathrm{mM} \mathrm{CO}_{2}$ in $\mathrm{MeCN} / \mathrm{H}_{2} \mathrm{O}$ has $\mathrm{pK}$ a $\left.=26.7\right) .{ }^{41}$ Use of low $\left[\mathrm{H}^{+}\right]$in $\mathrm{CV}$ experiments can be used to access a kinetic region where hydride formation rate is measured based on the shift in peak potential: with low $\left[\mathrm{H}^{+}\right]$the follow-up chemical steps in the catalytic cycle are suppressed by the low $\left[\mathrm{H}^{+}\right]$.

Scheme 3. Proposed $\mathrm{CO}_{2}$ reduction mechanism by $\mathbf{1}^{3-}$.

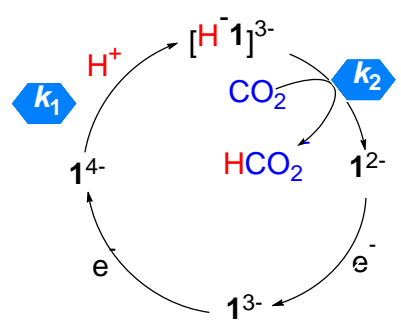


Accordingly, we collected CVs of $0.1 \mathrm{mM} \mathrm{1}^{2-}$ with $0.7 \%(0.38 \mathrm{mM}) \mathrm{H}_{2} \mathrm{O}$ in $0.1 \mathrm{M} \mathrm{Bu}_{4} \mathrm{NBF}_{4} \mathrm{MeCN}$ under $\mathrm{N}_{2}$ and under $\mathrm{CO}_{2}$ at $100 \mathrm{mV} / \mathrm{s}$ (Figure 2). Under $\mathrm{N}_{2}$, the reductive peak potential $E_{\mathrm{p}, \mathrm{c}}$ shifted anodically by $140 \mathrm{mV}$ relative to CV's absent $\mathrm{H}_{2} \mathrm{O}$ which suggests a fast rate for PT following the electron transfer (ET). For a chemical reaction that proceeds ET the peak potentials $\left(E_{\mathrm{p}}\right)$ shift cathodically relative to the formal potential of $\mathbf{1}^{3-/ 4-}\left(E_{1 / 2}\right)$ with increasing scan rate according to equation $1:{ }^{42,43}$

$$
E_{p}=E_{\frac{1}{2}}-\frac{0.78 R T}{F}+\frac{R T}{2 F} \ln \left(\frac{R T k_{1}}{F v}\right)
$$

where $R$ is ideal gas constant (8.314 $\left.\mathrm{Jmol}^{-1} \mathrm{~K}^{-1}\right)$; $T$ is temperature $(K) ; F$ is Faraday's constant $\left(\mathrm{C} \mathrm{mol}^{-1}\right) ; k_{1}$ is the second-order rate constants of the PT reaction $\left(\mathrm{s}^{-1}\right.$, and $\mathrm{mol}^{-1} \mathrm{~cm}^{3} \mathrm{~s}^{-1}$, respectively); and other symbols were defined earlier. A plot of $\left(E_{\mathrm{p}}-E_{1 / 2}\right) \mathrm{F} / \mathrm{RT}$ vs $\ln (\mathrm{v})$ according to equation (1) gave $k_{1}=6.3 \times 10^{5} \mathrm{M}^{-1} \mathrm{~s}^{-1}$ under $1 \mathrm{~atm}$ $\mathrm{N}_{2}$ (Table 1, Figure 2 top, Calculation S2). The same experiment was repeated under $1 \mathrm{~atm} \mathrm{CO}_{2}$ and a slightly higher rate of $1.2 \times 10^{7} \mathrm{M}^{-1} \mathrm{~s}^{-1}$ was observed for $k_{1}$ (Table 1 , Figure 2 bottom, Calculation S2). This higher rate for $k_{1}$ is consistent with carbonic acid as the proton source, which has lower $\mathrm{p} K_{\mathrm{a}}$ than $\mathrm{H}_{2} \mathrm{O}$ as proton source in $\mathrm{MeCN}$ (vide supra). The value of $k_{1}$ measured using $\mathrm{AnsdH}^{+}$as a proton source was the same (within error) under $1 \mathrm{~atm}$ of $\mathrm{N}_{2}$ or $\mathrm{CO}_{2}$ and is $3 \times 10^{8} \mathrm{M}^{-1} \mathrm{~s}^{-1}$ (Table 1 , Figure S6, Calculation S2).
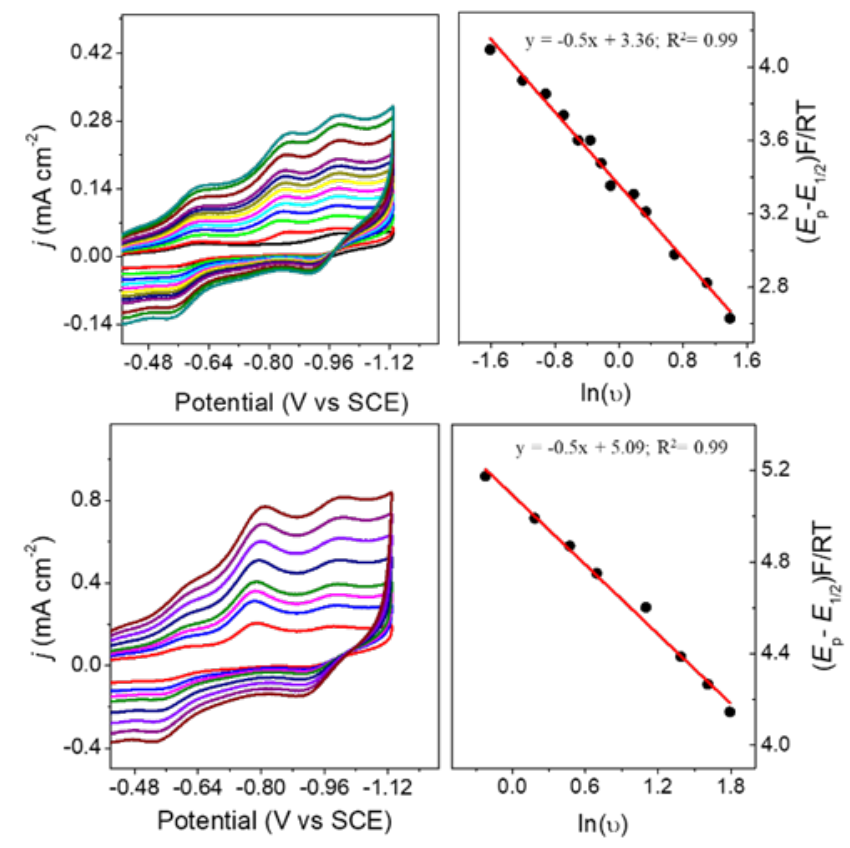

Figure 2. CVs of $0.1 \mathrm{mM} \mathrm{1}^{2-}$ in $0.1 \mathrm{M} \mathrm{Bu}_{4} \mathrm{NBF}_{4} \mathrm{MeCN} / \mathrm{H}_{2} \mathrm{O}$ (99.3:0.7). (top) Under $1 \mathrm{~atm} \mathrm{~N}_{2}$ at variable scan rates (starting from bright green $0.2,0.3,0.4,0.5,0.6,0.7,0.8,0.9,1.2,1.4,1.6 \mathrm{Vs}^{-1}$ ); CV in black is for $\mathbf{1}^{2-}$ without added $\mathrm{H}_{2} \mathrm{O}$ ). (bottom) Under 1 atm $\mathrm{CO}_{2}$ at variable scan rates (starting from red trace 0.8, 1.2, 1.6, 2, 3, 4, 5 and $\left.6 \mathrm{Vs}^{-1}\right)$. (Right) Plots of $\left(E_{\mathrm{p}}-E_{1 / 2}\right)(\mathrm{F} / \mathrm{RT}) \mathrm{vs} \ln (v)$. The red line is a linear fit with slope -0.5 . 
Table 1. Rate constants, $k_{1}$ and $k_{2}$, for hydride formation and formate formation, respectively, by $\mathbf{1}^{3-}$.

\begin{tabular}{lllllll}
\hline $\begin{array}{l}{\left[\mathrm{H}^{+}\right]} \\
/ \mathrm{mM}\end{array}$ & $\mathrm{pKa}$ & $\begin{array}{l}E_{\mathrm{cat} / 2} \\
/ \mathrm{V}\end{array}$ & $\begin{array}{l}k_{1}{ }^{a} \\
/ \mathrm{M}^{-1} \mathrm{~s}^{-1}\end{array}$ & $\begin{array}{l}k_{2}{ }^{b} \\
/ \mathrm{M}^{-1} \mathrm{~s}^{-1}\end{array}$ & $\begin{array}{l}k_{\text {obs }} \\
/ \mathrm{s}^{-1}\end{array}$ \\
\hline $\mathrm{H} 2 \mathrm{O}(380)$ & $30.7-41$ & $\mathrm{~N}_{2}$ & -0.82 & $6.3 \times 10^{5}$ & - & - \\
$\mathrm{H} 2 \mathrm{O}(308)$ & 26.6 & $\mathrm{CO}_{2}$ & -0.77 & $1.2 \times 10^{7}$ & - & - \\
$\mathrm{H}_{2} \mathrm{O}(2800)$ & 26.6 & $\mathrm{CO}_{2}$ & -0.94 & - & 126 & 30 \\
$\mathrm{AnsdH}^{+}(0.15)^{c}$ & 11.9 & $\mathrm{~N}_{2}$ & -0.76 & $3 \times 10^{8}$ & - & - \\
$\mathrm{AnsdH}^{+}(2)$ & 11.9 & $\mathrm{CO}_{2}$ & -0.78 & - & 103 & 28 \\
$\mathrm{AnsdH}^{+}(0.25)$ & 11.9 & $\mathrm{CO}_{2}$ & -0.78 & $4.6 \times 10^{8}$ & - & - \\
\hline
\end{tabular}

Measured in $0.1 \mathrm{mM} \mathrm{Bu}_{4} \mathrm{NBF}_{4} \mathrm{MeCN}$ with $\mathrm{H}_{2} \mathrm{O}$ or $\mathrm{AnsdH}^{+}$as $\mathrm{H}^{+}$source, under 1 atm $\mathrm{CO}_{2}$ or $\mathrm{N}_{2}$. $E_{1 / 2}\left(1^{3-/ 4-}\right)=-$ $0.95 \mathrm{~V} .{ }^{a} k_{1}$ calculated using peak shift analysis (equation 1 , Calculation S2). ${ }^{b} k_{2}$ and $k_{\text {obs }}$ obtained from FOWA (Calculation S3). ' See ref (37).

A plot of the $k_{1}$ vs. $\mathrm{p} K_{\mathrm{a}}$ for three different acids ( $\mathrm{p} K_{\mathrm{a}}=11.86, \mathrm{AnsdH}^{+} ; 26.7, \mathrm{H}_{2} \mathrm{CO}_{3}$; and 39-41, $\mathrm{MeCN} / \mathrm{H}_{2} \mathrm{O}$ ) shows a linear relationship similar to the linear free energy relationship (LFER) associated with hydride formation by for other metal complexes (Figure S7). The self-consistency of these data further confirm the accuracy of our measurements of $k_{1}$ and the $\mathrm{p} K_{\mathrm{a}}$ values we used for $\mathrm{H}_{2} \mathrm{O}$ and carbonic acid in MeCN solution; ${ }^{40,41}$ the plots also suggest that the kinetic influence of multiple protonation sites on the Co clusters is relatively similar for $\mathbf{1}^{2-}$ and for $\left[\mathrm{Co}_{13} \mathrm{C}_{2}(\mathrm{CO})_{24}\right]^{4-.36,37}$

Mechanistic Studies of Hydride Transfer. Our next effort toward understanding the kinetic effects which enhance the performance metrics of formate production by $\mathbf{1}^{2-}$ was to characterize the chemistry under reaction conditions that promote turnover in a catalytic cycle. CV experiments were performed with varied [1 $\left.\mathbf{1}^{2-}\right]$ in $0.1 \mathrm{M}$ $\mathrm{Bu}_{4} \mathrm{NBF}_{4} \mathrm{MeCN}$ under $\mathrm{CO}_{2}$, and the acid source was either $5 \%$ (2.77 M) $\mathrm{H}_{2} \mathrm{O}$ or $2 \mathrm{mM} \mathrm{AnsdH}^{+}$(Figure 3). In each case, a linear correlation between $j_{\mathrm{c}}$ vs. [1 $\left.^{2-}\right]$ was observed and this indicates that formate production is first order in $\left[\mathbf{1}^{2-}\right]$. The reaction is first order with respect to $\left[\mathrm{H}^{+}\right]$under $1 \mathrm{~atm} \mathrm{CO}_{2}$ when either $\mathrm{H}_{2} \mathrm{O}$ or $\mathrm{AnsdH}^{+}$is the source of $\mathrm{H}^{+}$(Figure $\mathrm{S} 8$ ).

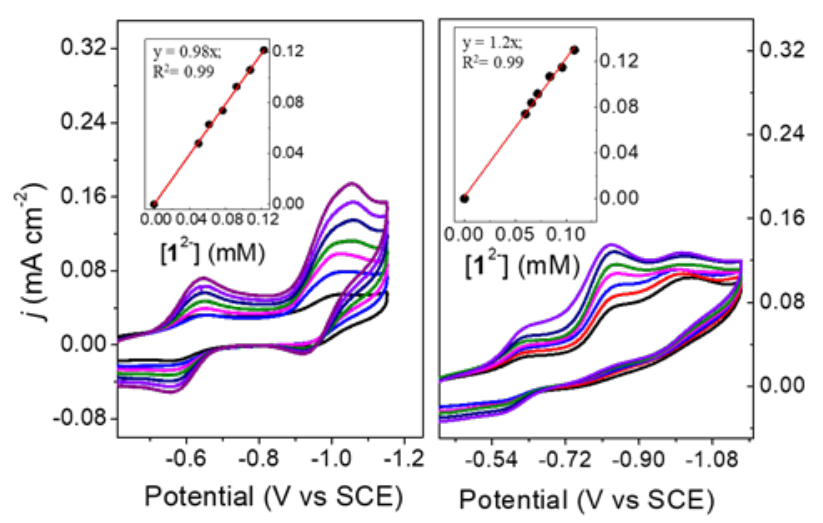

Figure 3. CVs of $\mathbf{1}^{2-}$ with $\left(0.05,0.06,0.77,0.09,0.11\right.$, and $0.12 \mathrm{mM} \mathrm{H}^{+}$, colors) in $0.1 \mathrm{M} \mathrm{Bu}_{4} \mathrm{NBF}_{4} \mathrm{MeCN}$ under $\mathrm{CO}_{2}$, at $100 \mathrm{mV} / \mathrm{s}$ and using GC electrode. (left) with $5 \% \mathrm{H}_{2} \mathrm{O}$ as source of $\mathrm{H}^{+}$. Inset: plot of $j_{\mathrm{c}}$ vs. [1 ${ }^{2-}$, at -1.054

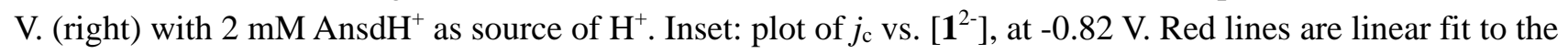
data and black $\mathrm{CV}$ trace has no added $\mathrm{H}^{+}$. 
The rate of hydride transfer to $\mathrm{CO}_{2}$ is the rate-limiting step in the catalytic cycle for formate production, and since formation of $(\mathrm{H}-\mathbf{1})^{3-}$ is so fast, its concentration must be building up during catalysis. This should provide a kinetic boost to the observed rate of formate formation and measurements of $k_{2}$ using CV provide the observed rate for formate formation. The rate of formate formation by $\mathbf{1}^{3-}$ was measured with two different sources of protons: AnsdH ${ }^{+}$and $\mathrm{H}_{2} \mathrm{O}$. The CV's collected under these two conditions were analysed using a foot of the wave (FOW) analysis (Calculation S3, Tables S2, S3, and Figures S9 - S13). A FOW analysis in this system provides a value for $k_{2}$ (hydride transfer to $\mathrm{CO}_{2}$ ) because that is the chemical step which follows the more favorable ET event (Scheme 1) ${ }^{44,45}$ Based on the FOW analyses we determined values for $k_{2}$ that are 127 and $100 \mathrm{M}^{-1} \mathrm{~s}^{-1}$, respectively, in $\mathrm{MeCN} / \mathrm{H}_{2} \mathrm{O}$ (95:5) and $\mathrm{MeCN}$ with added $\mathrm{AnsdH}^{+}$, under $1 \mathrm{~atm} \mathrm{CO}_{2}$ (Table 1). Under $1 \mathrm{~atm}$ of $\mathrm{CO}_{2}$, the $\left[\mathrm{CO}_{2}\right]$ in $\mathrm{MeCN} / \mathrm{H}_{2} \mathrm{O}(95: 5)$ is $0.24 \mathrm{M}^{46}$ or $0.28 \mathrm{M}$ in $\mathrm{MeCN}$ with $\mathrm{AnsdH}^{+}$, and then $k_{\text {obs }}$ can be calculated using equation 2:

$$
k_{\mathrm{obs}}=k_{2}\left[\mathrm{CO}_{2}\right]
$$

where $k_{\mathrm{obs}}$ is the observed rate of reaction $\left(\mathrm{s}^{-1}\right) ; k_{2}$ is second order rate constant for the hydride transfer $\left(\mathrm{M}^{-1} \mathrm{~s}^{-1}\right)$; and $\left[\mathrm{CO}_{2}\right]$ is the concentration of $\mathrm{CO}_{2}(\mathrm{M})$. This gives $k_{\text {obs }}$ as $30 \mathrm{~s}^{-1}$ in $\mathrm{MeCN} / \mathrm{H}_{2} \mathrm{O}$ (95:5), and $28 \mathrm{~s}^{-1}$ in $\mathrm{MeCN}$ with AnsdH'.

A brief note regarding kinetic influences on rate, when $5 \%$ water is added to MeCN as proton source. The rate for formate formation by $\mathbf{1}^{3-}$ is $127 \mathrm{M}^{-1} \mathrm{~s}^{-1}$ in $\mathrm{MeCN} / \mathrm{H}_{2} \mathrm{O}$ and this $25 \%$ enhancement in rate may arise from hydrogen bond stabilization of the transition state structure for hydride transfer, ${ }^{28,29}$ relative to that observed when Ans $\mathrm{dH}^{+}$was used as proton source, in which case the rate for formate formation is $100 \mathrm{M}^{-1} \mathrm{~s}^{-1}$.

Benchmarking Kinetic Effects Using a Tafel-Style Plot. As mentioned in the introduction we predicted that two features of the catalyst performance would receive a kinetic enhancement due to the multiple surface sites for protonation using $\mathbf{1}^{3-}$, relative to reports of formate formation by other molecular catalysts. These two effects are nicely illustrated using a Tafel style plot which we show for two different proton sources, $\mathrm{AnsdH}^{+}$and $\mathrm{H}_{2} \mathrm{O}$ (Figures 4, S14).

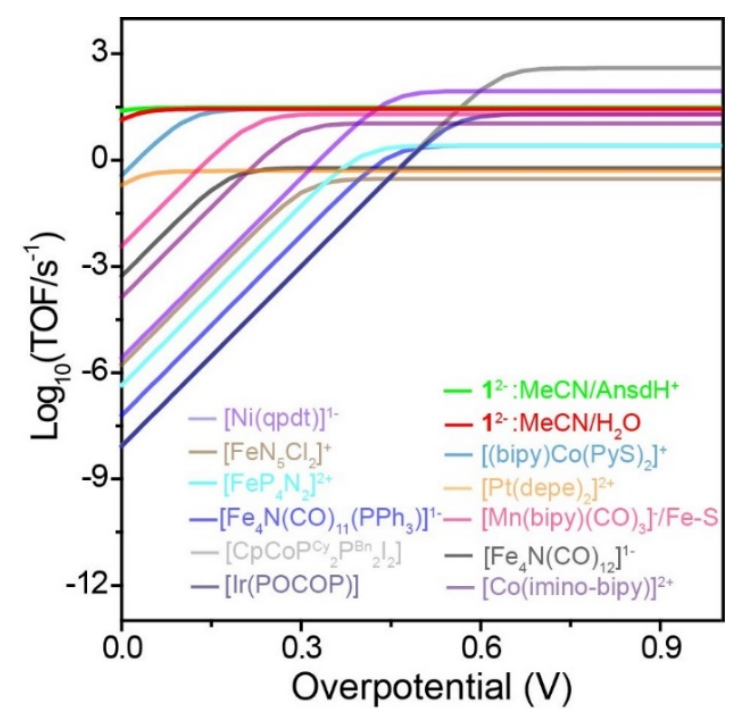

Figure 4. Tafel-style plot: $\log _{10}\left(\mathrm{TOF} / \mathrm{s}^{-1}\right)$ vs Overpotential $(\eta)$ at $E_{\mathrm{cat} / 2}$, for selected molecular $\mathrm{CO}_{2}$ to $\mathrm{HCO}_{2}{ }^{-}$reduction catalysts. Details of calculations and parameters used to construct the plot are in Table S5 and references therein. 
Kinetic Enhancement of Hydride Formation Rate $\left(\boldsymbol{k}_{\mathbf{1}}\right)$. Kinetic enhancements to $k_{1}$ result in a very low overpotential for the catalytic reaction, which is close to thermoneutral, at $10 \mathrm{mV}$ using $\mathbf{1}^{3-}$ in $\mathrm{MeCN} / \mathrm{AnsdH}^{+}$. Specifically, $E_{1 / 2}$ for $\mathbf{1}^{3-}$ is $-0.95 \mathrm{~V}$ but $E_{\text {cat } / 2}$ is $-0.76 \mathrm{~V}$ and the $180 \mathrm{mV}$ anodic shift in $E_{\text {cat } / 2}$ has a kinetic origin in the extremely fast PT rate and formation of $(\mathrm{H}-\mathbf{1})^{3-}$, at $3 \times 10^{8} \mathrm{M}^{-1} \mathrm{~s}^{-1}$. This kinetic enhancement of $(\mathrm{H}-\mathbf{1})^{3-}$ formation rate is attributed to multiple sites for protonation on the surface of $\mathbf{1}^{3-}$. Molecular catalysts usually have just one protonation site and so formation of the intermediate hydride is most often the rate determining step in the catalytic cycle and then $E_{1 / 2}$ is roughly equivalent to $E_{\mathrm{cat} / 2}$. An example of a very fast formate forming catalyst is [(bipy)Co(PyS $\left.)_{2}\right]^{+}$and in that case the overall rate for formate formation is similar to $\mathbf{1}^{3-}$ while the overpotential remains pinned to the value of $E_{1 / 2}$ so that the overpotential for formate formation is $110 \mathrm{mV}$ (Figure 4). ${ }^{47}$

Kinetic Enhancement of Hydride Transfer Rate $\left(\boldsymbol{k}_{\mathbf{2}}\right)$. The second kinetic enhancement of performance arises from a build-up in concentration of $(\mathrm{H}-\mathbf{1})^{3-}$ during catalysis because $(\mathrm{H}-\mathbf{1})^{3-}$ is formed at a rate that is five-orders of magnitude faster than the rate at which it is consumed. Similarly, very recently Miller and coworkers demonstrated that if the kinetic energy barrier for hydride formation is very low, then the following hydride transfer step should give higher rate even at low temperature due to accumulation of hydride intermediate. ${ }^{48}$ The observed rate ( $k_{\text {obs }}$ or TOF) for hydride transfer to $\mathrm{CO}_{2}$ can be thought of then in the simplest terms, as determined by both the kinetic enhancement due to high concentration of $(\mathrm{H}-\mathbf{1})^{3-}$ and also from the thermochemical driving force related to the hydricity of $(\mathrm{H}-\mathbf{1})^{3-}$.

Hydricity $\left(\Delta G_{\mathrm{H}-}\right)$ is the free energy for loss of hydride from a hydride donor such as (H-1 $)^{3-}$, and - absent kinetic effects - a linear free energy relationship (LFER) exists between $\log \left(\mathrm{TOF} / \mathrm{s}^{-1}\right)$ and $E_{\text {cat/2 }}$ over a series of catalysts. ${ }^{49}$ A plot of $E_{\text {cat } 2}$ vs $\log _{10}\left(\mathrm{TOF} / \mathrm{s}^{-1}\right)$ for molecular catalyst for $\mathrm{CO}_{2}$ to formate is expected to show a LFER where TOF increases linearly with increasing driving force (Figure 5). The unique molecular design for $\mathbf{1}^{3-}$ compared to other reported catalyts for formate formation is apparent from the higher rate at very low overpotential in this comparison group.

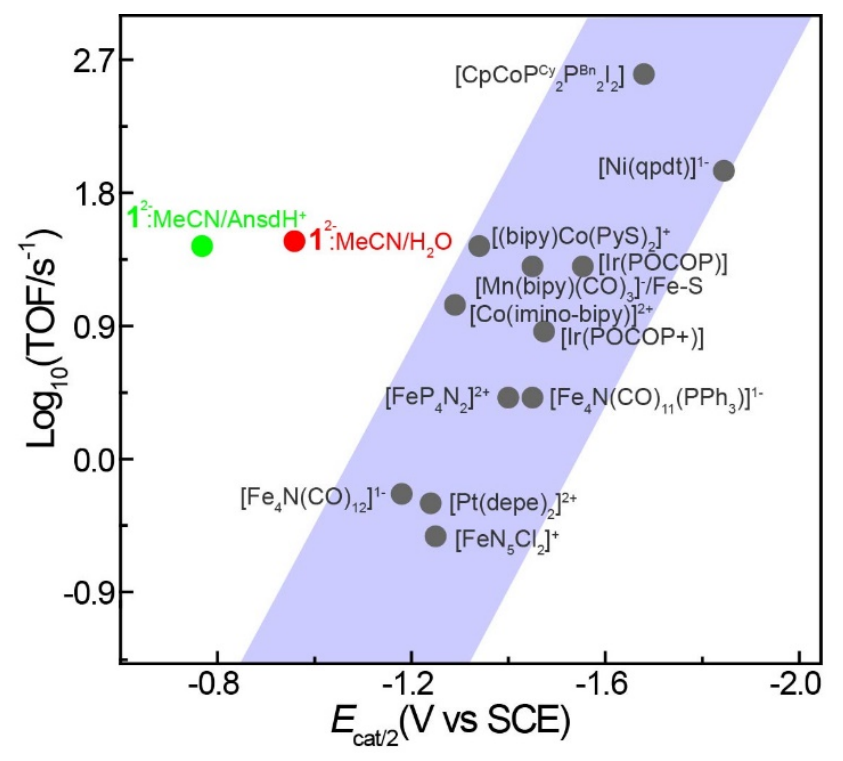

Figure 5. Linear free energy relationship between $\log _{10}\left(\mathrm{TOF} / \mathrm{s}^{-1}\right)$ and $E_{\mathrm{cat} / 2}$ for selected molecular electrocatalysts. $\left(\mathbf{1}^{2-},\left[\mathrm{Fe}_{4} \mathrm{~N}(\mathrm{CO})_{12}\right]^{1-},{ }^{12,27}\left[\mathrm{Fe}_{4} \mathrm{~N}(\mathrm{CO})_{12}\right]^{1-}: \mathrm{H}_{2} \mathrm{O},{ }^{27}\left[\mathrm{Fe}_{4} \mathrm{~N}(\mathrm{CO})_{11}\left(\mathrm{PPh}_{3}\right)\right]^{-}{ }^{50}\left[\mathrm{FeN}_{5} \mathrm{Cl}_{2}\right]^{+},{ }^{51}\left[\mathrm{FeP}_{4} \mathrm{~N}_{2}\right]^{2+},{ }^{52}\right.$ $\left[\mathrm{Co}(\text { imino-bpy) }]^{2+},{ }^{53}\left[\text { (bipy)Co(PyS) }{ }_{2}\right]^{+},{ }^{47} \mathrm{CpCoP}_{2} \mathrm{~N}^{\mathrm{Bn}}{ }_{2} \mathrm{I}_{2},{ }^{25}[\mathrm{Ni} \text { (qpdt) }]_{2}\right]^{-54}{ }^{54}$ Pt(depe $\left.)_{2}\right]^{+},{ }^{22,23} \mathrm{Ir}(\mathrm{POCOP})^{29}$ and $[\mathrm{Mn}$ (bipy)(CO) 3$] / \mathrm{Fe} \mathrm{S} .{ }^{32}$ Data for this plot, see Table S5. The blue shadow highlights correlation of $\log _{10}\left(\mathrm{TOF} / \mathrm{s}^{-}\right.$ $\left.{ }^{1}\right)$ with $E_{\text {cat } / 2}$ for selected molecular catalysts. 
Thermochemical Correlation with Hydride Transfer Rate $\left(\boldsymbol{k}_{\mathbf{2}}\right)$. The Tafel-style plots above provide a nice visualization of performance comparison. However. comparisons of rate vs hydricity provide a more precise visualization of the kinetic enhancements to rate over the intrinsic thermochemical driving force for hydride transfer. Therefore, we experimentally determined that $\Delta G_{\mathrm{H}-}$ for $(\mathrm{H}-1)^{3-}$ is $41.1 \pm 2.6 \mathrm{kcalmol}^{-1}$ in $\mathrm{MeCN}$ when using an

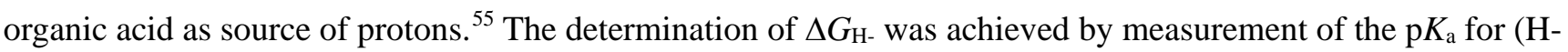
1) ${ }^{3-}$ using infra-red spectroelectrochemical measurements, and then calculation of $\Delta G_{\mathrm{H}-}$ using a thermochemical cycle (Calculation S5, Figure S15). ${ }^{56,57,5812,16}$ The $\Delta G_{\mathrm{H}-}$ for formate in MeCN is $44 \mathrm{kcalmol}^{-1}$ and that suggests that reaction of $(\mathrm{H}-\mathbf{1})^{3-}$ with $\mathrm{CO}_{2}$ to give $\mathbf{1}^{2-}$ and $\mathrm{HCOO}^{-}$is favorable by $2.9 \mathrm{kcalmol}^{-1}$ which is relatively close to thermoneutral. Other example catalysts which have hydricity close to thermoneutral for $\mathrm{C}-\mathrm{H}$ bond formation with $\mathrm{CO}_{2}$ include $\left[\mathrm{Fe}_{4} \mathrm{~N}(\mathrm{CO})_{11}\left(\mathrm{PPh}_{3}\right)\right]^{-50},{ }^{50} \mathrm{Pt}(\mathrm{dmpe})_{2},{ }^{21}$ and $\left[(\mathrm{bipy}) \mathrm{Co}(\mathrm{PyS})_{2}\right]^{+},{ }^{47}$ which have $\Delta G_{\mathrm{H}-}$ estimated at $45,41.4$, and $38 \mathrm{kcalmol}^{-1}$, respectively. We note that the hydricity for $\left[\mathrm{H}-\mathrm{Fe}{ }_{4} \mathrm{~N}(\mathrm{CO})_{11}\left(\mathrm{PPh}_{3}\right)\right]^{-}$and $\left[\mathrm{H}-\mathrm{Pt}(\mathrm{dmpe})_{2}\right]^{18}$ were determind experimentally, and for [(bipy)Co(PyS $\left.)_{2}\right]^{+}$a theoretical estimate was made. The catalysts $\mathbf{1}^{3-}$ and $\left[\mathrm{Pt}(\mathrm{dmpe})_{2}\right]^{2+}$ have near-identical hydricity but $\mathbf{1}^{3-}$ produces formate with a rate that is five orders of magnitude faster. Another direct comparison involves [(bipy)Co(PyS $\left.)_{2}\right]^{+}$which has hydricity $3.1 \mathrm{kcalmol}^{-1}$ stronger than $\mathbf{1}^{3-}$ and yet the two catalyst exhibit near-identical rates: $100 \mathrm{M}^{-1} \mathrm{~s}^{-1}$ for $\mathbf{1}^{3-}$, and $98.2 \mathrm{M}^{-1} \mathrm{~s}^{-1}$ for [(bipy)Co(PyS) $]^{+}$in MeCN. Both of these comparisons - to Pt(dmpe $)_{2}$ and to [(bipy)Co(PyS $\left.)_{2}\right]^{+}$- highlight the kinetic enhancement in rate relative to the rate that is expected based on the thermochemical properties (hydricity) of $\mathbf{1}^{3-}$.

\section{Conclusion}

In this report, we described a molecular electrocatalyst $\left[\mathrm{Co}_{11} \mathrm{C}_{2}(\mathrm{CO})_{23}\right]^{3-}\left(\mathbf{1}^{3-}\right)$ which converts $\mathrm{CO}_{2}$ into formate with fast rate, $127 \mathrm{M}^{-1} \mathrm{~s}^{-1}$ in a process that is close to thermoneutral. Selectivity for formate formation (over $\mathrm{H}_{2}$ formation or other $\mathrm{CO}_{2}$ reduction products) arises from the thermoneutral reaction profile whereas molecularly designed kinetic effects promote the fast rate. Specifically, a statistical effect derived from multiple catalyst sites available for protonation creates a diffusion-limited rate for formation of the catalyst hydride intermediate, $(\mathrm{H}-1)^{3-}$ , and that rate is $3 \times 10^{8} \mathrm{M}^{-1} \mathrm{~s}^{-1}$. The subsequent hydride transfer to $\mathrm{CO}_{2}$ has a rate of $127 \mathrm{M}^{-1} \mathrm{~s}^{-1}$ which is kinetically enhanced relative to the rate predicted based on the hydride donor ability of $(\mathrm{H}-1)^{3-}$.

More generally, these findings illustrate a catalyst design strategy using a nanoscale, molecularly defined catalyst, where multiple catalyst sites for protonation (hydride formation, $k_{1}$ ) can kinetically lower catalytic overpotential. In addition, the fast hydride formation rate leads to a high concentration of catalyst-hydride intermediate and a kinetic effect that enhances the rate for hydride transfer $\left(k_{2}\right)$. Both of these kinetic influences operate without destroying the thermochemically-derived selectivity for formate. The generality and clearly understood origin of these effects should be applicable in hydride transfer to substrates other than $\mathrm{CO}_{2}$ and applied to the design of other homogeneous and heterogeneous catalysts where multiple protonation sites can be built into the catalyst architecture.

\section{Supporting Information}

Experimental Methods, Calculations, CPE results, CV measurements and details of Electrochemical analysis, PDF.

\section{Acknowledgement}

This manuscript is based upon work supported by the Department of Energy, Office of Science, Basic Energy Sciences with award number DE-SC0016395. We thank the Keck Imaging facility and Dr. A. Karsai for assistance with SEM-EDX. We thank Prof. T. Guo and Ms. Mengqi for assistance with dynamic light scattering.

\section{References}


(1) Nitopi, S.; Bertheussen, E., Scott, S. B., Liu, X., Engstfeld, A. K., Horch, S., Seger, B., Stephens, I. E. L., Chan, K., Hahn, C., Norskov, J. K., Jaramillo, T. F. \& Chorkendorff, I. Progress and Perspectives of Electrochemical $\mathrm{CO}_{2}$ Reduction on Copper in Aqueous Electrolyte. Chem. Rev. 119, 7610-7672 (2019).

(2) Olah, G. A., Goeppert, A. \& Surya Prakash, G. K. J. Org. Chem. 74, 487-498 (2009).

(3) Olah, G. A., Goeppert, A. \& Surya Prakash, G. K. Beyond Oil and Gas: The Methanol Economy 2nd ed (Wiley-VCH, Weinheim, Germany, 2009).

(4) Chen, H., Dong, F. \& Minteer, S. D. The progress and outlook of bioelectrocatalysis for the production of chemicals, fuels and materials. Nat. Catal. 3, 225-244 (2020).

(5) De Luna, P., Hahn, C., Higgins, D., Jaffer, S. A., Jaramillo, T. F. \& Sargent, E. H. What would it take for renewably powered electrosynthesis to displace petrochemical processes? Science 364, No. eaav3506. (2019).

(6) Appel, A. M., Bercaw, J. E., Bocarsly, A. B., Dobbek, H., DuBois, D. L., Dupuis, M., Ferry, J. G., Fujita, E., Hille, R., Kenis, P. J., Kerfeld, C. A., Morris, R. H., Peden, C. H., Portis, A. R., Ragsdale, S. W., Rauchfuss, T. B., Reek, J. N., Seefeldt, L. C., Thauer, R. K. \& Waldrop, G. L. Frontiers, opportunities, and challenges in biochemical and chemical catalysis of CO 2 fixation. Chem. Rev. 113, 6621-6658 (2013).

(7) Inglis, J. L., MacLean, B. J., Pryce, M. T. \& Vos, J. G. Electrocatalytic Pathways towards Sustainable Fuel Production from Water and $\mathrm{CO}_{2}$. Coord. Chem. Rev. 256, 2571-2600(2012).

(8) Ross, M. B., De Luna, P., Li, Y., Dinh, C.-T., Kim, D., Yang, P. \& Sargent, E. H. Designing materials for electrochemical carbon dioxide recycling. Nat. Catal. 2, 648-658 (2019).

(9) Zhao, S., Jin, R. X. \& Jin, R. C. Opportunities and Challenges in $\mathrm{CO}_{2}$ Reduction by Gold- and Silver-Based Electrocatalysts: From Bulk Metals to Nanoparticles and Atomically Precise Nanoclusters. ACS Energy Lett. 3, 452-462 (2018).

(10) Zhang, S., Fan, Q., Xia, R. \& Meyer, T. J. CO $\mathrm{CO}_{2}$ Reduction: From Homogeneous to Heterogeneous Electrocatalysis. Acc. Chem. Res. 53, 255-264 (2020).

(11) Montoya, J. H., Seitz, L. C., Chakthranont, P., Vojvodic, A., Jaramillo, T. F. \& Nørskov, J. K. Materials for Solar Fuels and Chemicals. Nat. Mater. 16, 70-81 (2016).

(12) Taheri, A., Thompson, E. J., Fettinger, J. C. \& Berben, L. A. An Iron Electrocatalyst for Selective Reduction of $\mathrm{CO}_{2}$ to Formate in Water: Including Thermochemical Insights. ACS Catal. 5, 7140-7151 (2015).

(13) Costentin, C., Robert, M. \& Saveant, J.-M. Catalysis of the electrochemical reduction of carbon dioxide. Chem. Soc. Rev. 42, 2423-2436 (2013).

(14) Francke, R., Schille, B. \& Roemelt, M. Homogeneously Catalyzed Electroreduction of Carbon Dioxide-Methods, Mechanisms, and Catalysts. Chem. Rev. 118, 4631-4701 (2018).

(15) Zhang, S., Fan, Q., Xia, R. \& Meyer, T. J. CO 2 Reduction: From Homogeneous to Heterogeneous Electrocatalysis. Acc. Chem. Res. 53, 255-264 (2020).

(16) Taheri, A. \& Berben, L. A. Tailoring Electrocatalysts for Selective $\mathrm{CO}_{2}$ or $\mathrm{H}^{+}$Reduction: Iron Carbonyl Clusters as a Case Study. Inorg. Chem. 55, 378-385 (2016).

(17) Loewen, N. D., Neelakantan, T. V. \& Berben, L. A. Renewable Formate from C-H Bond Formation with CO 2 : Using Iron Carbonyl Clusters as Electrocatalysts. Acc. Chem. Res. 50, 2362-2370 (2017).

(18) Waldie, K. M., Ostericher, A. L., Reineke, M. H., Sasayama, A. F. \& Kubiak, C. P. Hydricity of Transition-Metal Hydrides: Thermodynamic Considerations for $\mathrm{CO}_{2}$ Reduction. ACS Catal. 8, 1313-1324 (2018).

(19) Ceballos, B. M. \& Yang, J. Y. Directing the reactivity of metal hydrides for selective $\mathrm{CO}_{2}$ reduction. Proc. Natl. Acad. Sci. U. S. A. 115, 12686-12691 (2018).

(20) Yang, J., Kerr, T., Wang, X. \& Barlow, J. Reducing $\mathrm{CO}_{2}$ to $\mathrm{HCO}_{2}{ }^{-}$at Mild Potentials: Lessons from Formate Dehydrogenase. J. Am. Chem. Soc. 142, 19438-19445 (2020).

(21) Barlow, J. M. \& Yang, J. Y. Thermodynamic Considerations for Optimizing Selective $\mathrm{CO}_{2}$ Reduction by Molecular Catalysts. ACS Cent. Sci. 5, 580-588 (2019).

(22) Cunningham, D. W., Barlow, J. M., Velazquez, R. S. \& Yang, J. Y. Reversible and Selective $\mathrm{CO}_{2}$ to $\mathrm{HCO}_{2}{ }^{-}$Electrocatalysis near the Thermodynamic Potential. Angew. Chemie - Int. Ed. 59, 4443-4447 (2020).

(23) Cunningham, D. W. \& Yang, J. Y. Kinetic and Mechanistic Analysis of a Synthetic Reversible $\mathrm{CO}_{2} / \mathrm{HCO}_{2}{ }^{-}$Electrocatalyst. Chem. Commun. 56, 12965-12968 (2020).

(24) Fogeron, T., Todorova, T. K., Porcher, J. P., Gomez-Mingot, M., Chamoreau, L. M., Mellot-Draznieks, C., Li, Y. \& Fontecave, M. A Bioinspired Nickel(Bis-Dithiolene) Complex as a Homogeneous Catalyst for Carbon Dioxide Electroreduction. ACS Catal. 8, 2030-2038 (2018).

(25) Roy, S., Sharma, B., Pécaut, J., Simon, P., Fontecave, M., Tran, P. D., Derat, E. \& Artero, V. Molecular Cobalt Complexes with Pendant Amines for Selective Electrocatalytic Reduction of Carbon Dioxide to Formic Acid. J. Am. Chem. Soc. 139, 3685-3696 (2017).

(26) Loewen, N. D. \& Berben, L. A. Secondary Coordination Sphere Design to Modify Transport of Protons and CO 2 . Inorg. Chem. 58, 16849-16857 (2019). 
(27) Taheri, A., Carr, C. R. \& Berben, L. A. Electrochemical Methods for Assessing Kinetic Factors in the Reduction of $\mathrm{CO}_{2}$ to Formate: Implications for Improving Electrocatalyst Design. ACS Catal. 8, 5787-5793 (2018).

(28) Sullivan, B. P. \& Meyer, T. J. Kinetics and Mechanism of Carbon Dioxide Insertion into a Metal-Hydride Bond. A Large Solvent Effect and an Inverse Kinetic Isotope Effect. Organometallics 5, 1500- 1502 (1986).

(29) Kang, P., Cheng, C., Chen, Z., Schauer, C. K., Meyer, T. J. \& Brookhart, M. Selective Electrocatalytic Reduction of $\mathrm{CO}_{2}$ to Formate by Water-Stable Iridium Dihydride Pincer Complexes. J. Am. Chem. Soc. 134, 5500-5503 (2012).

(30) Kang, P., Meyer, T. J. \& Brookhart, M. Selective Electrocatalytic Reduction of Carbon Dioxide to Formate by a WaterSoluble Iridium Pincer Catalyst. Chem. Sci. 4, 3497- 3502 (2013).

(31) Mayberry, D. D., Linehan, J. C. \& Appel, A. M. Designing Catalytic Systems Using Binary Solvent Mixtures: Impact of Mole Fraction of Water on Hydride Transfer._Inorg. Chem. 60, 17132-17140 (2021).

(32) Dey, S., Masero, F., Brack, E., Fontecave, M. \& Mougel, V. Electrocatalytic Metal Hydride Generation Using Concerted Proton Electron Transfer Mediators. 10.33774/chemrxiv-2021-18tth; This content is a preprint and has not been peer-reviewed.

(33) Madsen, M. R., Rønne, M. H., Heuschen, M., Golo, D., Ahlquist, M. S. G., Skrydstrup, T., Pedersen, S. U. \& Daasbjerg, K. Promoting Selective Generation of Formic Acid from $\mathrm{CO}_{2}$ Using $\mathrm{Mn}(\mathrm{Bpy})(\mathrm{CO})_{3} \mathrm{Br}$ as Electrocatalyst and Triethylamine/Isopropanol as Additives. J. Am. Chem. Soc. (2021). https://doi.org/10.1021/jacs.1c10805.

(34) Bhattacharya, M., Sebghati, S., Vanderlinden, R. T. \& Saouma, C. T. Toward Combined Carbon Capture and Recycling: Addition of an Amine Alters Product Selectivity from CO to Formic Acid in Manganese Catalyzed Reduction of $\mathrm{CO}_{2} . \mathrm{J}$. Am. Chem. Soc. 142, 17589-17597 (2020).

(35) Cesari, C., Shon, J. H., Zacchini, S. \& Berben, L. A. Metal Carbonyl Clusters of Groups 8-10: Synthesis and Catalysis. Chem. Soc. Rev. 50, 9503-9539 (2021).

(36) Carr, C. R., Taheri, A. \& Berben, L. A. Fast Proton Transfer and Hydrogen Evolution Reactivity Mediated by $\left[\mathrm{Co}_{13} \mathrm{C}_{2}(\mathrm{CO})_{24}\right]^{4-}$. J. Am. Chem. Soc. 142, 12299-12305 (2020).

(37) Pattanayak, S. \& Berben, L. A. Cobalt Carbonyl Clusters Enable Independent Control of Two Proton Transfer Rates in the Mechanism for Hydrogen Evolution. ChemElectroChem 8, 2488-2494 (2021).

(38) Helm, M. L., Stewart, M. P., Bullock, R. B., DuBois, M. R. \& DuBois, D. L. A Synthetic Nickel Electrocatalyst with a Turnover Frequency Above 100,000 s${ }^{-1}$ for $\mathrm{H}_{2}$. Science 333, 863-866 (2011).

(39) Ciabatti, I., Femoni, C., Hayatifar, M., Iapalucci, M. C., Longoni, G., Pinzino, C., Solmi, M. V. \& Zacchini, S. The Redox Chemistry of $\left[\mathrm{Co}_{6} \mathrm{C}(\mathrm{CO})_{15}\right]^{2-:}$ : A Synthetic Route to New Co-Carbide Carbonyl Clusters. Inorg. Chem. 53, 3818-3831 (2014).

(40) Felton, G. A. N., Vannucci, A. K., Okumura, N., Lockett, L. T., Evans, D. H., Glass, R. S. \& Lichtenberger, D. L. Hydrogen Generation from Weak Acids: Electrochemical and Computational Studies in the $\left[\left(\eta^{5}-\mathrm{C}_{5} \mathrm{H}_{5}\right) \mathrm{Fe}(\mathrm{CO})_{2}\right]_{2}$ System. Organometallics 27, 4671-4679 (2008).

(41) Riplinger, C. \& Carter, E. A. Influence of Weak Bronsted Acids on Electrocatalytic $\mathrm{CO}_{2}$ Reduction by Manganese and Rhenium Bipyridine Catalysts. ACS Catal. 5, 900-908 (2015).

(42) Savéant, J. -M. Elements of Molecular and Biomolecular Electrochemistry (John Wiley \& Sons, Hoboken, 2006)

(43) Lee, K. J., Elgrishi, N., Kandemir, B. \& Dempsey, J. L. Electrochemical and Spectroscopic Methods for Evaluating Molecular Electrocatalysts. Nat. Rev. Chem. 1, 0039, (2017).

(44) Wang, V. C. C. \& Johnson, B. A. Interpreting the Electrocatalytic Voltammetry of Homogeneous Catalysts by the Foot of the Wave Analysis and Its Wider Implications. ACS Catal. 9, 7109-7123 (2019).

(45) Costentin, C. \& Savéant, J.-M. Multielectron, Multistep Molecular Catalysis of Electrochemical Reactions: Benchmarking of Homogeneous Catalysts. ChemElectroChem 1, 1226-1236 (2014).

(46) Tomita, Y., Teruya, S., Koga, O. \& Hori, Y. Electrochemical Reduction of Carbon Dioxide at a Platinum Electrode in Acetonitrile-Water Mixtures. J. Electrochem. Soc. 147, 4164-4167 (2000).

(47) Dey, S., Todorova, T. K., Fontecave, M. \& Mougel, V. Electroreduction of $\mathrm{CO}_{2}$ to Formate with Low Overpotential Using Cobalt Pyridine Thiolate Complexes. Angew. Chemie 132, 15856-15863 (2020).

(48) Hu, J., Bruch, Q. J. \& Miller, A. J. M. Temperature and Solvent Effects on $\mathrm{H}_{2}$ Splitting and Hydricity: Ramifications on $\mathrm{CO}_{2}$ Hydrogenation by a Rhenium Pincer Catalyst. J. Am. Chem. Soc. 143, 945-954 (2021).

(49) Jeletic, M. S., Hulley, E. B., Helm, M. L., Mock, M. T., Appel, A. M., Wiedner, E. S. \& Linehan, J. C. Understanding the Relationship between Kinetics and Thermodynamics in $\mathrm{CO}_{2}$ Hydrogenation Catalysis. ACS Catal. 7, 6008-6017 (2017).

(50) Loewen, N. D., Thompson, E. J., Kagan, M., Banales, C. L., Myers, T. W., Fettinger, J. C. \& Berben, L. A. A Pendant Proton Shuttle on $\left[\mathrm{Fe}_{4} \mathrm{~N}(\mathrm{CO})_{12}\right]^{-}$Alters Product Selectivity in Formate vs. $\mathrm{H}_{2}$ Production via the Hydride $\left[\mathrm{H}-\mathrm{Fe}_{4} \mathrm{~N}(\mathrm{CO})_{12}\right]^{-}$. Chem. Sci. 7, 2728-2735 (2016).

(51) Chen, L., Guo, Z., Wei, X., Gallenkamp, C., Bonin, J., Lau, K., Lau, T. \& Robert, M. Molecular Catalysis of the Electrochemical and Photochemical Reduction of $\mathrm{CO}_{2}$ with Earth-Abundant Metal Complexes. Selective Production of $\mathrm{CO}$ vs HCOOH by Switching of the Metal Center. J. Am. Chem. Soc. 137, 10918-10921 (2015).

(52) Bi, J., Hou, P., Liu, F. \& Kang, P. Electrocatalytic Reduction of $\mathrm{CO}_{2}$ to Methanol by Iron Tetradentate Phosphine Complex Through Amidation Strategy. ChemSusChem 12, 2195 -2201 (2019). 
(53) Liu, F., Bi, J., Sun, Y., Luo, S. \& Kang, P. Cobalt Complex with Redox-Active Imino Bipyridyl Ligand for Electrocatalytic Reduction of Carbon Dioxide to Formate. ChemSusChem 11,1656 -1663 (2018).

(54) Fogeron, T.; Todorova, T. K.; Porcher, J.; Gomez-mingot, M.; Chamoreau, L.; Mellot-draznieks, C.; Li, Y.; Fontecave, M. A Bioinspired Nickel(Bis-Dithiolene) Complex as a Homogeneous Catalyst for Carbon Dioxide Electroreduction. ACS Catal. 2018, 8, 2030-2038.

(55) The theoretical framework developed by Kubiak and coworkers, ${ }^{18}$ estimates hydricity for $(\mathrm{H}-1)^{3-}$ as $49.8 \mathrm{kcalmol}^{-1}$ in MeCN solution (Calculation S6, Figure S14), but this assumes that bond dissociation free energy (BDFE) of metal hydride bonds varies only within $\pm 10 \mathrm{kcal} / \mathrm{mol}$, and is likely not a good approximation for the delocalized and fluctional bonding in clusters.

(56) Curtis, C. J.; Miedaner, A.; Ellis, W. W.; DuBois, D. L. Measurement of the Hydride Donor Abilities of [HM(Diphosphine $\left.)_{2}\right]^{+}$Complexes $(\mathrm{M}=\mathrm{Ni}, \mathrm{Pt})$ by Heterolytic Activation of Hydrogen. J. Am. Chem. Soc. 2002, 124, 19181925.

(57) Matsubara, Y.; Fujita, E.; Doherty, M. D.; Muckerman, J. T.; Creutz, C. Thermodynamic and Kinetic Hydricity of Ruthenium(II) Hydride Complexes. J. Am. Chem. Soc. 2012, 134, 15743-15757.

(58) Wiedner, E. S.; Chambers, M. B.; Pitman, C. L.; Bullock, R. M.; Miller, A. J. M.; Appel, A. M. Thermodynamic Hydricity of Transition Metal Hydrides. Chem. Rev. 2016, 116, 8655-8692.

\section{Table of Contents Graphic}




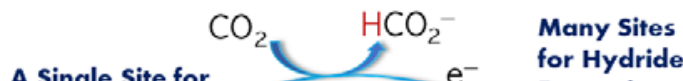

A Single Site for
Hydride Transfer $1 \mathrm{O}^{2} \mathrm{M}^{-1} \mathrm{~s}^{-1} \mathrm{e}^{-}$Formation

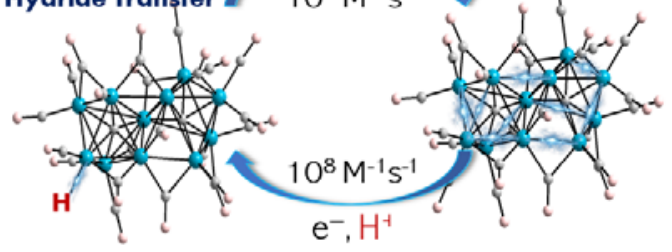

Cluster-Hydride Kinetic Boost

Concentration Enhanced $\longrightarrow$ for Formate

by Fast Hydride Formation Formation Rate 